\title{
Desenvolvimento urbano em áreas de fronteira: o caso do Itaim Paulista
}

\author{
Urban development in border areas: the case of Itaim Paulista
}

Ana Paula Koury ${ }^{[a]}$, Talita Veiga Cavallari ${ }^{[b]}$

${ }^{[a]}$ Universidade São Judas Tadeu (USJT), Programa de Pós-graduação em Arquitetura e Urbanismo, São Paulo, SP, Brasil
${ }^{[b]}$ Prefeitura Municipal de São Paulo, Departamento de Urbanismo e Licenciamento, São Paulo, SP, Brasil

\section{Resumo}

A política de adensamento da cidade de São Paulo propôs o aumento da área construída em regiões específicas da cidade, para aproximar trabalho e moradia. Como esta estratégia funciona nas áreas periféricas da cidade? A política de adensamento da cidade de São Paulo foi definida pela Rede de Estruturação da Transformação Urbana, proposta pela Lei Municipal n.o 16.050/2014 - Plano Diretor Estratégico (PDE) - e pela Lei Municipal n.. 16.402/2016 - conhecida como Lei de Zoneamento. 0 foco deste trabalho é analisar o caso de um bairro periférico, considerando que a dinâmica dessas áreas é muito diferente da dinâmica do centro da cidade, em que políticas de desenvolvimento urbano baseadas no adensamento têm sido aplicadas há pelo menos duas décadas. 0 estudo de caso apresentado é o da Estrada Dom João Nery, localizada no Itaim Paulista, zona leste da cidade.

Palavras-chave: Política urbana. Plano diretor. Lei de zoneamento. Itaim Paulista.

\section{Abstract}

The densification policy of São Paulo City proposes an increase of built area in specific regions of the São Paulo City to connect jobs and housing. How this strategy works in the peripheral areas of the city? The policy of densification was defined by the Structuring Network of Urban Transformation (SNUT), proposed in the Municipal Law n. 16.050 / 2014 - Strategic Master Plan (SMP) and in the Municipal Law n. 16.402/2016, better known as the Zoning Law. The goal is to analyze the application of the policy in a peripheral neighborhood, considering the different dynamic in this area compared to downtown, where this type of policy has being applied for at least two decades. This article studies the case ofDom João Nery Road, in the Itaim Paulista neighborhood, east zone of São Paulo city.

Keyword: Urban policy. Master plan. Zoning law. Itaim Paulista.

APK é doutora em estruturas ambientais urbanas, Professora Programa de Pós-graduação em Arquitetura e Urbanismo, Universidade São Judas Tadeu, e-mail: apkoury@gmail.com

TVC é mestre pelo Programa de Pós-graduação em Arquitetura e Urbanismo da Universidade São Judas Tadeu, Secretária executiva FUNDURB - SMUL, e-mail: tcavallari@prefeitura.sp.gov.br 


\section{Introdução}

Após a aprovação do Estatuto da Cidade (Lei n.․ㅜ 10.257, de 10 de julho de 2001) (Brasil,2001) e a obrigatoriedade de elaboração dos planos diretores municipais, muitos trabalhos têm avaliado criticamente os instrumentos definidos pela lei federal, principalmente os planos diretores municipais elaborados após 2001, reconhecendo limites que só puderam ser verificados depois de um conjunto de experiências recentes (Villaça, 2005; Martins, 2006; Bueno \& Cymbalista, 2007; Maricato, 2011; Rolnik, 2013; Santos \& Montandon, 2011). Alguns trabalhos analisam principalmente os instrumentos especiais de zoneamento e seu impacto nos setores informais da cidade (Abramo, 2003; Denaldi, 2009; Fernandes, 2003). Também foram objeto de estudo as operações urbanas e os mecanismos de produção de mais-valia liderados pela iniciativa privada (Somekh \& Campos, 2005).

Desde a publicação do livro São Paulo: crescimento e pobreza (Kowarick \& Caldeira Brant, 1976), um conjunto importante de trabalhos tem se dedicado ao estudo das periferias urbanas. Estes estudos enfatizaram a condição de crescimento urbano na precariedade de assentamentos periféricos, que caracterizou a intensa urbanização concentrada brasileira e da maioria dos países latino-americanos. Entretanto, pesquisas realizadas a partir da década de 1980 têm chamado a atenção para a transformação social e espacial das periferias urbanas da cidade de São Paulo, como é o caso do trabalho pioneiro de Caldeira $(1984,2005)$.

Por outro lado, os estudos publicados pelo Centro de Estudos da Metrópole têm permitido reavaliar a dinâmica dos investimentos públicos e da urbanização nos bairros da Zona Leste da cidade de São Paulo (Marques \& Bichir, 2002), colocando em questão uma parte da literatura consagrada na área de urbanismo sobre as periferias paulistanas. Pesquisa recente da Fundação Perseu Abramo (2017), com moradores desses setores da cidade de São Paulo, apontou a necessidade de ampliar as pesquisas sobre o tema com o objetivo de esclarecer como os moradores das periferias paulistanas percebem o Estado e as políticas públicas.

Os estudos urbanos sobre o bairro do Itaim Paulista (Anelli \& Leitão, 2014; Lara \& Koury, 2016) têm procurado enfrentar o desafio das interpretações transdisciplinares que relacionam a legislação urbanística e o desenho da cidade. 0 objetivo é testar a validade dos instrumentos formais de planejamento, especificamente a revisão do Plano Diretor de São Paulo (São Paulo, 2014b), analisando o seu impacto no desenho dos elementos urbanos, principalmente do sistema viário em uma localidade determinada, o Itaim Paulista. 0 presente estudo insere-se neste quadro, contribuindo para o debate sobre o impacto da política urbana e dos instrumentos de planejamento na gestão das periferias urbanas, analisando o caso da implantação do corredor de ônibus da Estrada Dom João Nery no bairro do Itaim Paulista, periferia leste da cidade de São Paulo. Este caso permite abordar o tema da participação popular na definição dos instrumentos de zoneamento da cidade, em área de difícil desenvolvimento urbano.

\section{A políitca de adensamento definida pela rede de estruturação da transformação urbana em São Paulo}

A política de adensamento da cidade de São Paulo foi basicamente definida pela Rede de Estruturação da Transformação Urbana, proposta pela Lei Municipal n. - 16.050/2014 - Plano Diretor Estratégico (São Paulo, 2014b) - e pela Lei Municipal n. $16.402 / 2016$ Parcelamento, Uso e Ocupação do Solo, mais conhecida como Lei de Zoneamento (São Paulo, 2016a).

A sanção das duas leis ocorreu no âmbito da revisão da Lei n.o 13.430/2002 (São Paulo, 2002), o antigo Plano Diretor de São Paulo, e da revisão da Lei de Zoneamento n.o 13.885/2004 (São Paulo, 2004). As novas Leis definiram diretrizes estruturais importantes para o desenvolvimento urbano da cidade. As dez diretrizes gerais básicas adotadas pela revisão do PDE e pela Lei de Zoneamento da cidade de São Paulo foram:

1. socializar os ganhos da produção da cidade; 2. qualificar a vida urbana nos bairros;

3. reorganizar as dinâmicas metropolitanas;

4. orientar o crescimento das cidades na proximidade do transporte público; 5. promover o desenvolvimento econômico da cidade; 6 . incorporar a agenda ambiental ao desenvolvimento da cidade; 7. preservar o patrimônio e valorizar as iniciativas culturais; 8. fortalecer a participação popular nas decisões dos rumos da cidade; 9. assegurar o direito à 
moradia digna para quem precisa; 10 . melhorar a mobilidade urbana (São Paulo, 2015a, p. 15).

A Lei de Parcelamento, Uso e Ocupação do Solo - Zoneamento (Lei Municipal n. ${ }^{-0}$ 13.885/2004) (São Paulo, 2004), revisada em 2016 (Lei Municipal n.o 16.402/2016) (São Paulo, 2016a), definiu um novo conjunto de regras para o parcelamento, uso e ocupação do solo. Isto significou alterar o modo como as edificações devem ser implantadas nos lotes e quais atividades (comércio, serviço, indústria etc.) podem ser instaladas nos diferentes locais da cidade.

Tanto a revisão da Lei de Zoneamento quanto a revisão da Lei do Plano Diretor, que foram aprovadas em 2016 e 2014, respectivamente, obedeceram ao princípio de participação popular. Ou seja: foram decisões compartilhadas com a população, cujo objetivo foi exatamente aproximar os instrumentos gerais de planejamento da cidade às necessidades concretas da população. Isto foi feito através de audiências e consultas públicas nas prefeituras regionais. As consultas permitiram incorporar as demandas da população na revisão das leis. A plataforma on-line na página da internet "Gestão Urbana" da Secretaria de Desenvolvimento Urbano da PMSP também ficou aberta para recolher sugestões do público. Agestão da cidade de São Paulo no período do Prefeito Fernando Haddad (2013-2016) procurou abrir, ao máximo, canais de escuta para a sociedade civil, honrando os compromissos da política urbana com a democracia brasileira, que foram definidos pela Constituição Federal de 1988 através do Artigo 182, posteriormente detalhado pela Lei Federal conhecida como Estatuto da Cidade em 2001. O PDE/2014 dividiu a cidade de São Paulo em duas Macrozonas, a Macrozona de Estruturação e Qualificação Urbana, e a Macrozona de Proteção e Recuperação Ambiental (Figura 1). Considerou-se a necessidade de adotar duas estratégias opostas de atuação: no primeiro caso, a intensificação de uso em áreas já urbanizadas, e no segundo caso, a necessidade de conter o avanço da urbanização em áreas de preservação e de proteção, e também na chamada "zona rural" localizada ao sul do município.

A Rede de Estruturação da Transformação Urbana é um instrumento previsto pelo PDE/2014 e pela Lei de Zoneamento/2016. Entre outras disposições, esta fornece diretrizes e incentivos para o adensamento e a diversificação de usos nas áreas envoltórias dos principais eixos de mobilidade localizados na Macrozona de Estruturação e Qualificação Urbana (Figura 2).
MACROZONAS

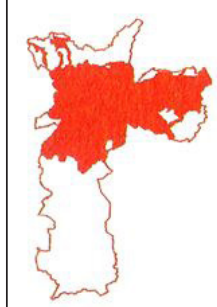

Macrozona de Estruturação e Qualificação Urbana

\section{Macrozona de Proteção e Recuperação Ambiental}

Figura 1 - Macrozonas PDE/2014

Fonte: São Paulo (2015a, p .44).

Inserido nessas duas leis, o instrumento de adensamento ao longo dos principais eixos viários, chamado Eixos de Estruturação da Transformação Urbana (EETU), seguiu o pressuposto geral de que os eixos viários de média ou alta capacidade - como metrô, corredor de ônibus ou ciclofaixas, existentes ou previstos - deveriam cumprir a sua função social de modo intensificado. Assim, nessas áreas, a Lei de Zoneamento/2016 elevou os coeficientes de aproveitamento. Isto significa que, nas áreas envoltórias da Rede Estrutural de Transporte Coletivo, que estão dentro da Macrozona de Estruturação Urbana, é permitido contruir até quatro vezes a área do terreno, enquanto, no restante da macrozona, que corresponde à área já urbanizada da cidade, o coeficiente básico de aproveitamento é apenas uma vez a área do terreno.

Além disso, foram definidos outros incentivos para essas áreas e seu entorno imediato: a fachada ativa, que tem como objetivo promover atividades ligadas ao comércio e serviço locais; a fruição pública, que tem como objetivo permitir o acesso da população ao interior da quadra; as calçadas mais largas, e o uso misto, que tem como objetivo associar moradia e trabalho.

O intuito do instrumento "Eixo de Estruturação da Transformação Urbana” é aproximar emprego, moradia e comércio local, intensificando e diversificando o uso e a ocupação do solo, e ampliando o acesso ao sistema de mobilidade urbana. A proposta visa fazer 
frente aos principais problemas da cidade: oferta de moradia, localização do emprego e transporte público de massa. As diretrizes gerais do instrumento Eixo de Estruturação da Transformação Urbana (EETU) foram apresentadas no PDE/2014 (São Paulo, 2014d) e depois complementadas pela Lei de Zoneamento/2016, que definiu parâmetros mais específicos para regular o uso, o parcelamento e a ocupação do solo nessas áreas.

Outras regulamentações complementares também foram incorporadas pela Lei de Zoneamento, como o tamanho mínimo de lote, a cota máxima de terreno por unidade habitacional, a proibição de muro contínuo, o tamanho mínimo de testada, as restrições para vagas de garagem e a largura mínima das calçadas. As medidas complementares foram definidas com o objetivo de proporcionar, para a região dos Eixos de Estruturação da Transformação Urbana (EETU), uma melhor convivência entre os diferentes usos e uma maior segurança para os cidadãos. Os instrumentos de planejamento e morfologia urbana definidos pela nova legislação em São Paulo são estratégias inovadoras que trazem grandes avanços para a reestruturação das áreas centrais da cidade.

Considerando-se que as estratégias incluídas na revisão da lei de zoneamento aproximam os objetivos gerais do planejamento e a realização da política urbana no campo da democracia brasileira, enfrentando assim uma das principais críticas de Villaça (2005), cumpre verificar a operatividade dos instrumentos da Lei de Zoneamento em um padrão periférico de assentamentos informais com um importante desenvolvimento e economia local, em parte baseados na informalidade, como é o caso do Itaim Paulista e da Estrada Dom João Nery.

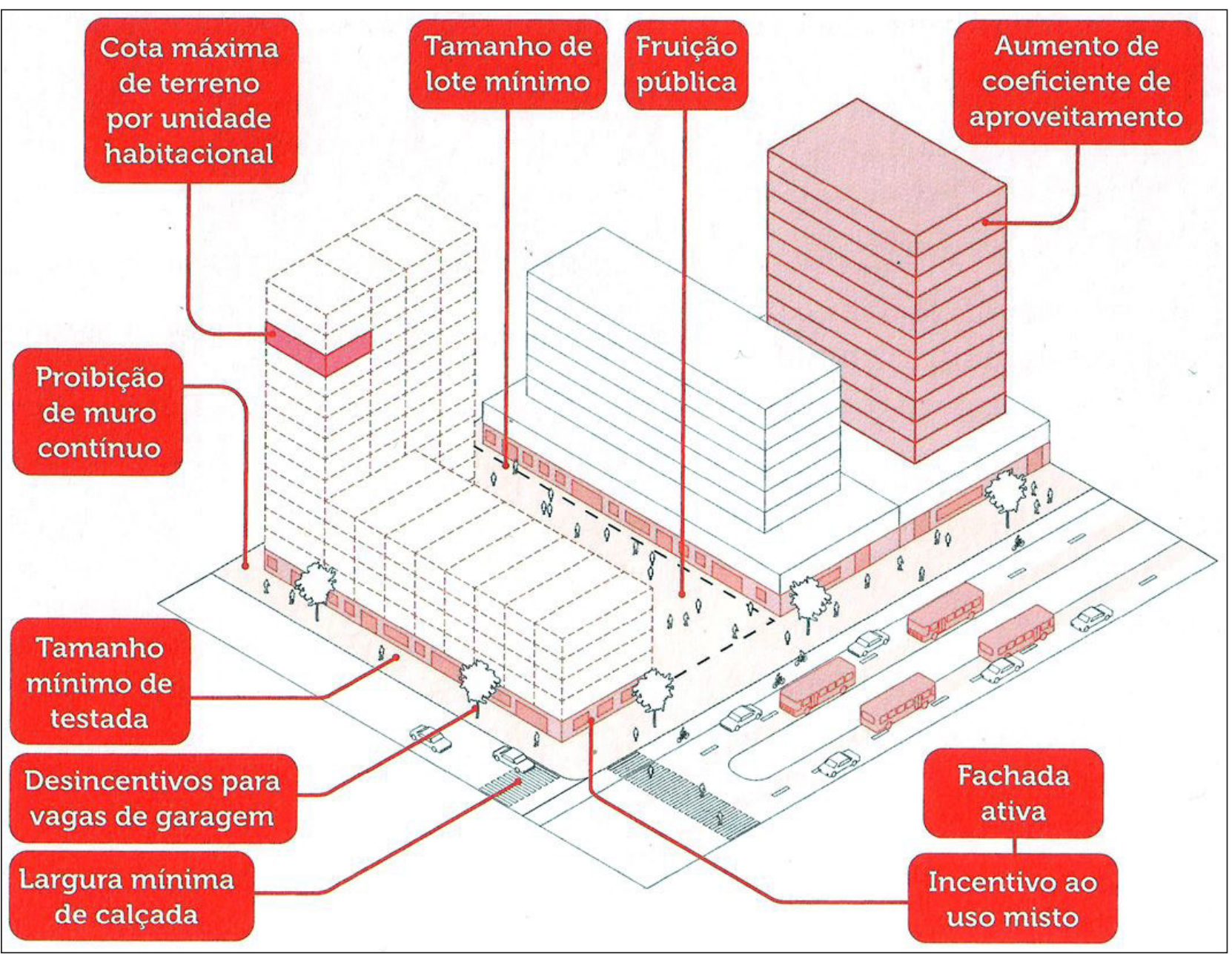

Figura 2 - Eixos de Estruturação da Transformaç̃ão Urbana PDE/2014 Fonte: São Paulo (2015a, p. 68). 


\section{Zoneamento em área de fronteira: o caso do Itaim Paulista}

O Itaim Paulista, assim como a maior parte das zonas leste e oeste da cidade de São Paulo, está localizado na Macrozona de Estruturação e Qualificação Urbana. Segundo a definição do PDE/2014, esta é a Macrozona que reúne os padrões diferenciados de urbanização e de uso e ocupação do solo, existentes nas diversas regiões da cidade. Nesta Macrozona, se apresenta reunida a grande desigualdade socioespacial de São Paulo, caracterizada pelos antigos padrões de urbanização, definidos como centros e periferias.

Na Macrozona de Estruturação e Qualificação Urbana, os padrões de urbanização foram agrupados em quatro conjuntos chamados de Macroáreas. A Macroárea de Urbanização Consolidada corresponde ao centro da cidade e aos bairros ao seu redor. A Macroárea de Estruturação Metropolitana corresponde à Rede de Transporte Estrutural, formada pelas marginais (orla fluvial) e pelas ferrovias (orla ferroviária) (Figura 3).

Os eixos correspondem aos "Arcos", sendo: da marginal do Rio Tietê (Arco Tietê); da conexão viária ao extremo leste da cidade pela Avenida Marechal Tito, paralelo à linha Férrea (Arco Leste); da Marginal do Rio Pinheiros (Arco Pinheiros); da conexão viária ao extremo sul da cidade (Arco Jurubatuba); da Marginal do Tamanduateí ou Avenida do Estado (Arco Tamanduateí), e da Avenida Jacu-Pêssego (Arco Jucu - Pêssego). As Macroáreas de Qualificação da Urbanização e de Redução da Vulnerabilidade correspondem às ocupações das periferias urbanas em seus diferentes graus de consolidação e de vulnerabilidade.

No caso das Macroáreas cuja urbanização ainda não está consolidada, os objetivos gerais são: i) promover uma convivência mais equilibrada entre a urbanização e a conservação ambiental, com a possibilidade de mudanças provenientes de grandes obras públicas e privadas; ii) promover sistemas de transporte coletivo

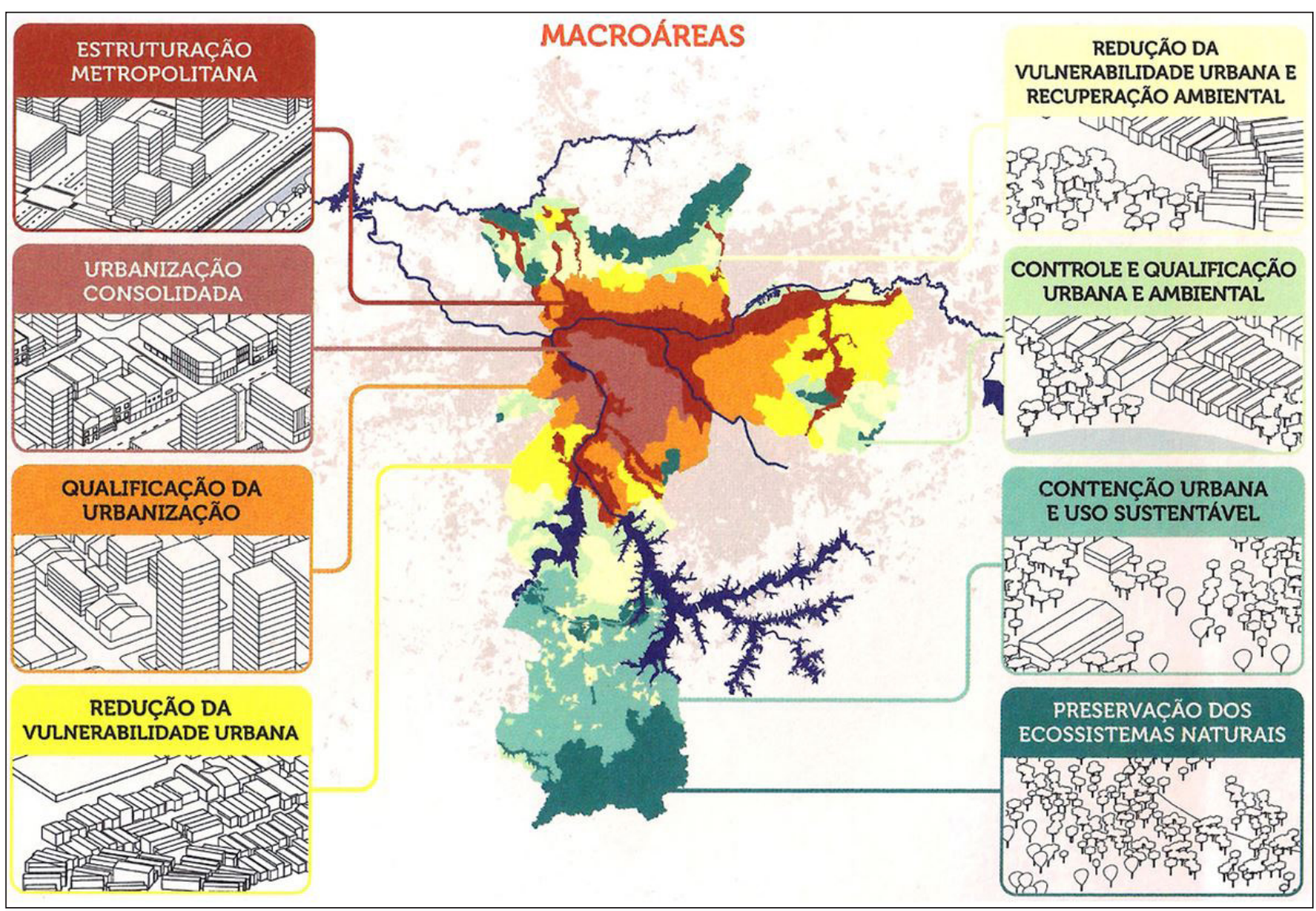

Figura 3 - Macroáreas PDE/2014. À esquerda, estão as macroáreas contidas na Macrozona de Estruturaçã̃o e Qualificação Urbana, e à direita, as macroáreas contidas na Macrozona de Proteção e Recuperacão Ambiental

Fonte: São Paulo (2015a, p. 44). 
e de infraestrutura; iii) orientar os processos da reestruturação urbana, possibilitados pelas novas leis; iv) fortalecer as bases da economia local e regional; v) eliminar e reduzir as situações de vulnerabilidade urbana, e vi) diminuir as desigualdades entre os distritos quanto a oferta e distribuição dos serviços, equipamentos e infraestruturas urbanas. Outro objetivo geral, que se aplica a todas as Macroáreas, inclusive àquelas de urbanização já consolidada, é manter, proteger e requalificar as zonas exclusivamente residenciais.

A região do Itaim Paulista (Figura 4) define-se por três Macroáreas. A Av. Marechal Tito, que é um importante eixo de ligação estrutural do bairro no sentido leste-oeste, faz parte da Macroárea de Estruturação Metropolitana. No bairro, há três polos de urbanização, definidos como Macroáreas de Qualificação da Urbanização. 0 primeiro faz divisa com São Miguel Paulista, à esquerda, e é formado pelo eixo da Rua Pedro Meira. 0 segundo eixo é polarizado pela Rua Tibúrcio de Souza, a algumas quadras abaixo da Avenida Rio Massambu, e a terceiro eixo é polarizado pela divisa do bairro com o Município de Itaquaquecetuba. Apesar da varidedade de padrões de urbanização existente no Bairro, a maior parte ainda pertence ao padrão relativo à Macroárea de Redução da Vulnerabilidade Urbana (Figura 5).

A Estrada Dom João Nery situa-se majoritariamente na Macroárea de Redução da Vulnerabilidade Urbana, sendo que, próximo à Avenida Marechal Tito, a Estrada corta a Macroárea de Estruturação metropolitana e,

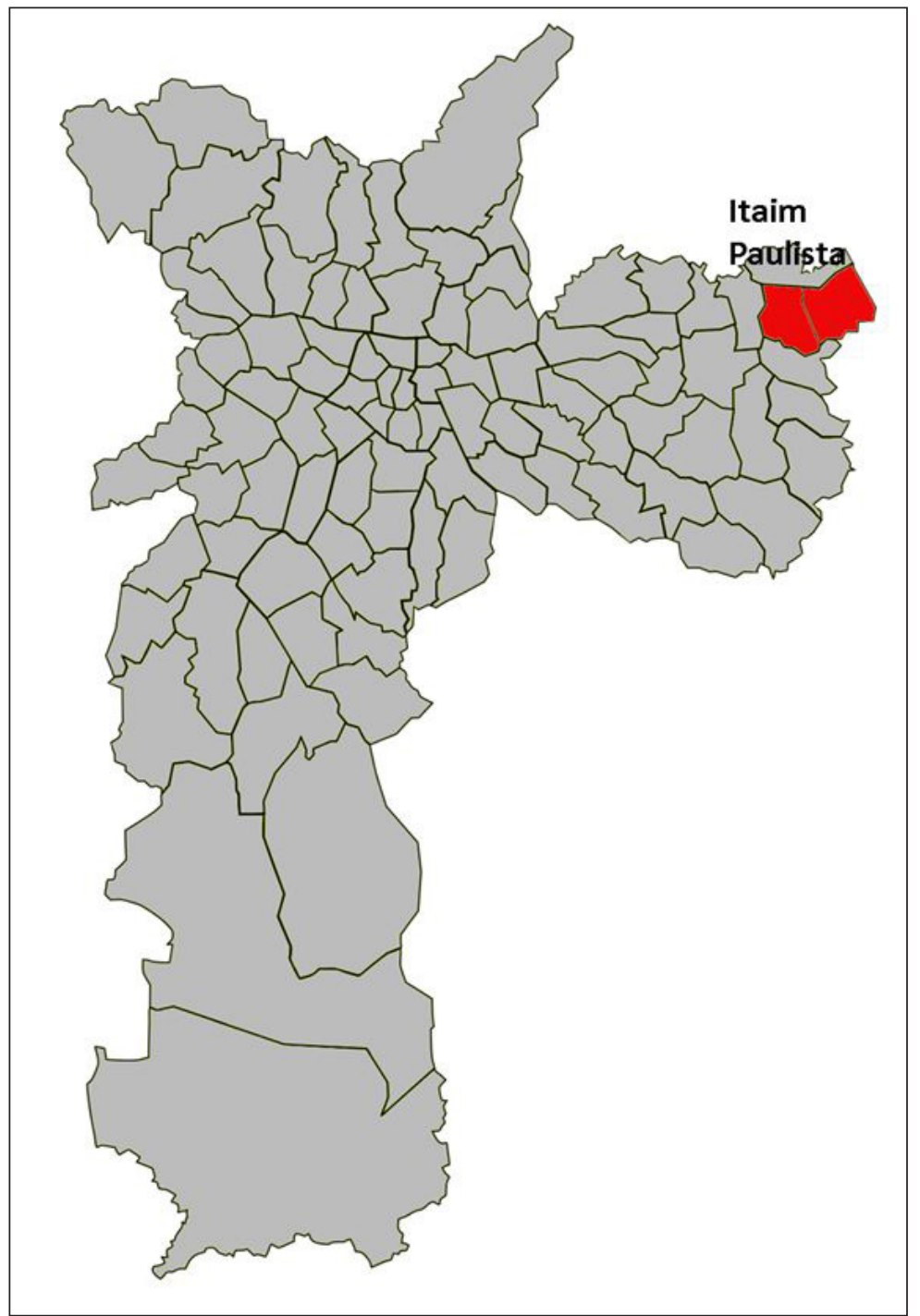

Figura 4 - Localização da Prefeitura Regional Itaim Paulista no Município de São Paulo Fonte: Alunos da Universidade São Judas Tadeu, 2015. 


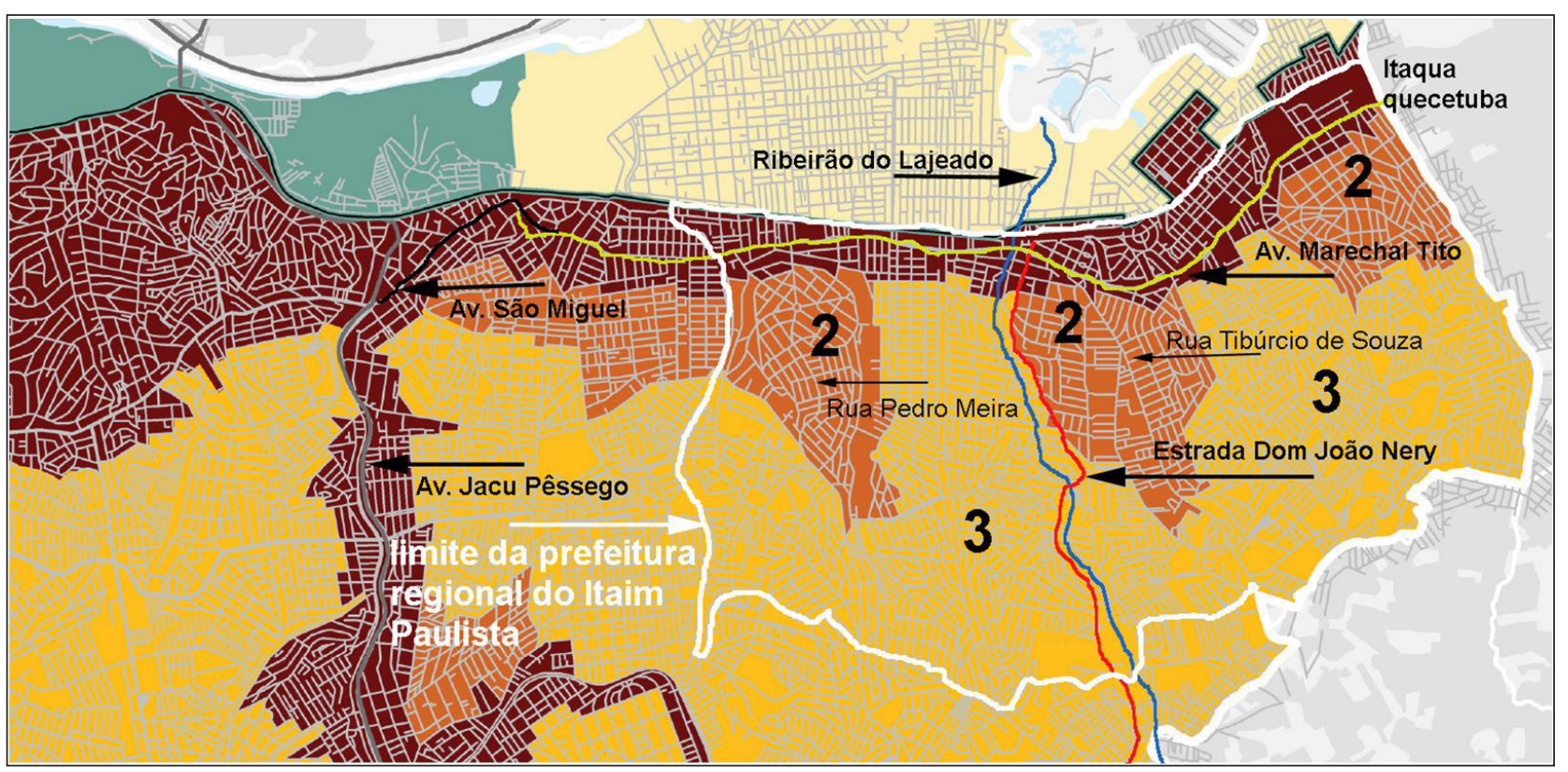

Figura 5 - Macroáreas: 1. Estruturação Metropolitana. 2. Qualificação da Urbanização Consolidada. 3. Redução da Vulnerabilidade Urbana Fonte: Mapa de desenvolvimento urbano (PDE/2014) (São Paulo, 2014d) com intervençōes das autoras.

logo ao sul, faz limite com a Macroárea de Qualificação da Urbanização polarizada pela Rua Tibúrcio de Souza.

A Macroárea de Redução da Vulnerabilidade Urbana, na qual a Estrada Dom João Nery se encontra, caracteriza-se pela existência de elevados índices de vulnerabilidade social; baixos índices de desenvolvimento humano, e ocupação por população predominantemente de baixa renda, em assentamentos precários e irregulares, além de carência na oferta de serviços, equipamentos e infraestruturas urbanas, dentre as quais se destaca a insuficiência de transporte coletivo. As principais irregularidades fundiárias presentes no bairro são as moradias em área de risco geológico, que corresponde às áreas de inundação dos seis córregos que cortam a região administrativa.

Os objetivos específicos definidos para o desenvolvimento urbano da Macroárea de Redução da Vulnerabilidade Urbana são: i) fortalecer a capacidade de proteção social a partir de melhorias nas condições de vida, de convivência e de acesso às políticas públicas; ii) incentivar usos não residenciais nos Eixos de Estruturação da Transformação Urbana e centralidades de bairro, para gerar empregos e reduzir a distância entre moradia e trabalho; iii) promover a urbanização e regularização fundiária dos assentamentos urbanos precários, para atrair e implantar serviços, equipamentos e infraestrutura urbana completa, e assim, garantir a segurança; iv) promover a construção de Habitação de
Interesse Social, e v) melhorar e completar o sistema de mobilidade urbana, com a integração entre os sistemas de transporte coletivo, ferroviário, viário, cicloviário e de circulação de pedestres.

Em relação ao zoneamento, as diretrizes de ocupação dos lotes, ao longo do corredor de ônibus proposto, são definidas pela Zona Eixo de Estruturação da Transformação Urbana Previsto (ZEUP), que visa promover o adensamento populacional, a diversificação de atividades, a intensificação da economia, a oferta de serviços públicos e a qualificação paisagística dos espaços públicos.

Para que o adensamento populacional seja efetivo, o Zoneamento previu, para a ZEUP, um Coeficiente de Aproveitamento Máximo, que pode chegar a 4, se atendidos todos os requisitos estabelecidos no Artigo 83 da Lei n. 16.050 (São Paulo, 2014b), com um gabarito máximo igual a 28 metros e uma Taxa de Ocupação de 0,85.

\section{Mobilidade em área de fronteira: o caso do corredor perimentral São Mateus/Itaim Paulista}

O Corredor de Ônibus nomeado Sistema Perimetral Itaim Paulista/São Mateus -Trecho III, que passa pela Estrada Dom João Nery, é parte de um grande empreendimento que está integrado a uma 
proposta abrangente de melhoria das condições de mobilidade da região metropolitana de São Paulo. Sua implantação serviria para melhorar as condições gerais de mobilidade da cidade de São Paulo e dos municipios que fazem parte do sistema metropolitano, impactando significativamente a população da região e as 373.127 pessoas que moram no Itaim Paulista, segundo as estimativas oficiais da prefeitura regional (São Paulo, 2010) (Figura 6).

0 projeto foi aprovado em 2016, por meio do Decreto n. - 56.834/2016 (São Paulo, 2016b), que instituiu o Plano de Mobilidade da Cidade de São Paulo (PlanMobSP/2015) (São Paulo, 2015b). O PlanMobSP/2015 baseia-se na Lei Federal n. ${ }^{-0}$ 12.587/2012 (Brasil, 2012), que instituiu a Política Nacional de Mobilidade Urbana, a qual, por sua vez, determina a elaboração do Plano de Mobilidade Urbana vinculado ao Plano Diretor de Desenvolvimento Urbano. O Plano de Mobilidade Urbana de São Paulo, tem como objetivo contribuir para universalizar o acesso à cidade, auxiliando na concretização das diretrizes do PDE e da Lei de
Zoneamento, em seu compromisso com a ampliação da democracia através da política urbana.

O Plano de Mobilidade Urbana de São Paulo é um documento elaborado pela Secretaria Municipal de Transportes (SMT) com a participação da São Paulo Transportes S/A (SPTrans) e da Companhia de Engenharia de Tráfego (CET), entre 2013 e 2015, para a gestão dos empreendimentos ligados ao sistema de mobilidade da cidade. Assim, incorpora propostas anteriores, como é o caso do Programa Municipal de investimentos e ações para a melhoria do transporte público coletivo e do trânsito para a cidade de São Paulo (São Paulo, 2013a), estabelecendo as prioridades e os objetivos gerais da política de mobilidade urbana da cidade.

O Programa Municipal de investimentos e ações baseia-se em um extensivo diagnóstico que, entre outras coisas, indica a piora das condições de mobilidade de toda a Região Metropolitana de São Paulo (RMSP) e aponta, como causas, a sobrecarga e a má qualidade do sistema viário existente, e a carência de atendimento às demandas por transporte público em algumas partes

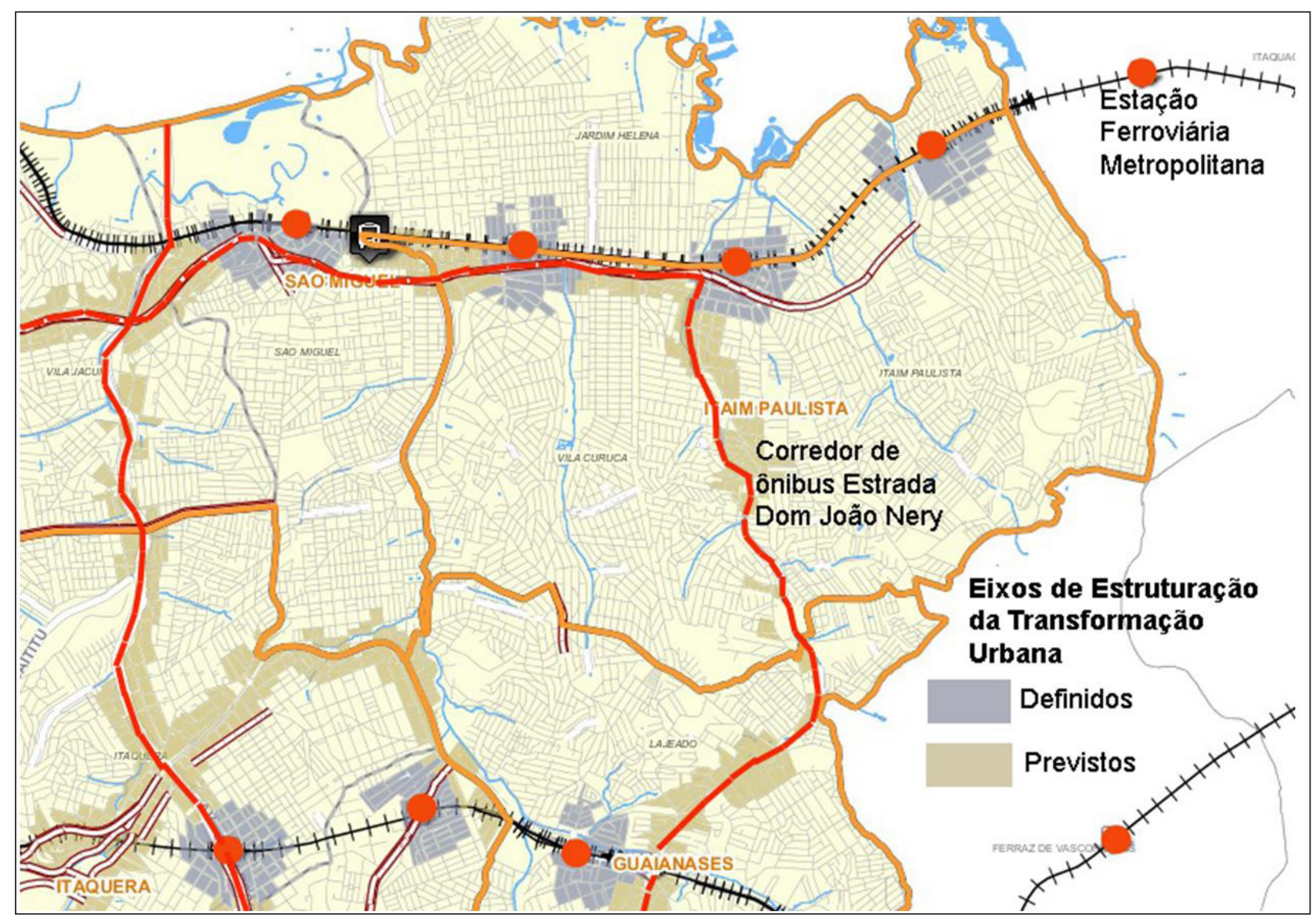

Figura 6 - Área de Influência do Eixo de Transformação da Estruturação Urbana (ZEUP) no Corredor da Estrada Dom João Nery Fonte: Mapa dos Eixos de Estruturação Metropolitana Lei n. ${ }^{0}$ 16.050/2014 (São Paulo, 2018) com intervenções das autoras. 
da cidade. Segundo o relatório, as consequências - além do aumento do tempo de viagens - são o aumento dos gastos com transporte, o aumento do número de acidentes graves e o aumento da poluição ambiental, entre outras (São Paulo, 2013a).

o Corredor de Ônibus do Sistema Perimetral Itaim Paulista/São Mateus -Trecho III, que passa pela Estrada Dom João Nery, faz parte de um conjunto de ações definidas pelo Programa Municipal de investimentos, que previu a implantação de 25 corredores de ônibus e 20 terminais. A implantação do programa foi dividida em duas etapas: a primeira, sob responsabilidade de SP Obras, incluía 10 corredores e cinco terminais, e a segunda, sob a responsabilidade da SP Trans, incluía 10 corredores (129 quilômetros) e 15 terminais. Esta etapa a ser implantada pela SPTrans, por sua vez, foi dividida em quatro regiões (Sul 1, Sul 2, Leste 1 e Leste 2). A Região Leste 2 é composta por três sistemas perimetrais: i) Bandeirantes - Salim Farah Maluf; ii) Itaim Paulista - São Mateus (trecho II — Av. João Batista Conti), e iii) Itaim Paulista - São Mateus (trecho III - Estrada Dom João Nery) — por um corredor radial - Corredor Radial Leste (trecho III — Avenida José Pinheiros Borges), e por três terminais: São Mateus, Vila Mara e Itaim Paulista (São Paulo, 2013b).

0 projeto do Corredor BRT Metropolitano Perimetral Leste já estava previsto pela Empresa Metropolitana de Transportes Urbanos de São Paulo (EMTU). A ideia deste corredor é promover a ligação direta entre dois importantes polos industriais da Região Metropolitana de São Paulo: o ABC e o município de Guarulhos, diferenciando-se da maioria dos corredores existentes, que têm ponto de origem ou ponto final na região central de São Paulo. O BRT Perimetral Leste pretende interligar dois grandes corredores de ônibus: o Corredor ABD (São Mateus - Jabaquara, que inclui a Estrada Dom João Nery) e o futuro Corredor Metropolitano Guarulhos - São Paulo (já concluído em sua primeira etapa, em 2013), com uma expectativa de que ocorra mudança do padrão de deslocamentos, reduzindo assim o número de viagens com ponto de parada na área central da Cidade de São Paulo. Os 175 mil usuários previstos pelo relatório EMTU Atividades (São Paulo, 2013) a serem transportados diariamente pelo novo Corredor ABD (São Mateus - Jabaquara, que inclui a Estrada Dom João Nery) terão acesso facilitado ao sistema metro-ferroviário metropolitano já existente.
As vantagens trazidas pela implantação do Plano são induscutíveis. 0 sistema Leste 2 , que implica na ligação entre os terminais do Itaim Paulista e de São Mateus, traria grande benefício para todos os moradores da região. A ligação entre os municípios de Guarulhos, Santo André e São Bernardo, além dos benefícios diretos, também reduziria muito a sobrecarga no sistema de mobilidade da Cidade de São Paulo.

Portanto, no caso dos planos de mobilidade da cidade de São Paulo, parece haver uma clara integração entre a política setorial de mobilidade e o planejamento geral da cidade, uma conquista importante dos planos diretores municipais implementados após a vigência do Estatuto da Cidade. Mas, ao contrário do que ocorreu em muitas cidades, no caso de São Paulo, as escalas municipais e metropolitanas de planejamento da rede encontram-se articuladas, o que representa um avanço no quadro geral dos planos diretores municipais, relatado por Santos \& Montandon (2011, p. 45-46). Mas, afinal, qual o problema do corredor de ônibus da Estrada Dom João Nery no Itaim Paulista?

\section{O caso da estrada Dom João Nery no Itaim Paulista}

O licenciamento dos terminais e dos sistemas viários Leste 2, que inclui o trecho da Estrada Dom João Nery, foi aprovado pelo Conselho Municipal do Meio Ambiente e Desenvolvimento Sustentável (CADES) através da Resolução n. ${ }^{\circ}$ 158/CADES/2014 de 27 de novembro (São Paulo, 2013c), que dispôs sobre o Parecer Técnico 067/CADES/13, elaborado pela Câmara Técnica II - Obras Viárias, Drenagem e Transporte, a qual analisou o Estudo de Impacto Ambiental (EIA) dos Terminais e Sistemas Viários da Região Leste 2. O Conselho Municipal do Meio Ambiente e Desenvolvimento Sustentável (CADES), através da Resolução 158 (São Paulo, 2013c, p. 37), definiu, entre as exigências a serem cumpridas pelo empreendedor, as seguintes:

17-) Apresentar a Manifestação da Secretaria Municipal de Saúde, relativa aos equipamentos sociais sob sua responsabilidade, diretamente afetados pela implantação dos Corredores da Região Leste 2, quais sejam: Unidade Básica de Saúde Dom João Neri (remanejamento) e Unidade Básica de Saúde Chabilândia (parcial). 
18-) Apresentar a Manifestação da Secretaria Municipal de Educação, relativa aos equipamentos sociais sob sua responsabilidade, diretamente afetados pela implantação dos Corredores da Região Leste 2, quais sejam: EMEI Prof $\stackrel{a}{a}$ Doracil Dina Benício (parcial) e EMEF Padre Chico Falcone (parcial) (Figuras 7 e 8).

A Lei Municipal n.o $16.020 / 2014$ de 2 de Julho (São Paulo, 2014c) aprovou e regulou os melhoramentos necessários à implantação do Plano de Mobilidade

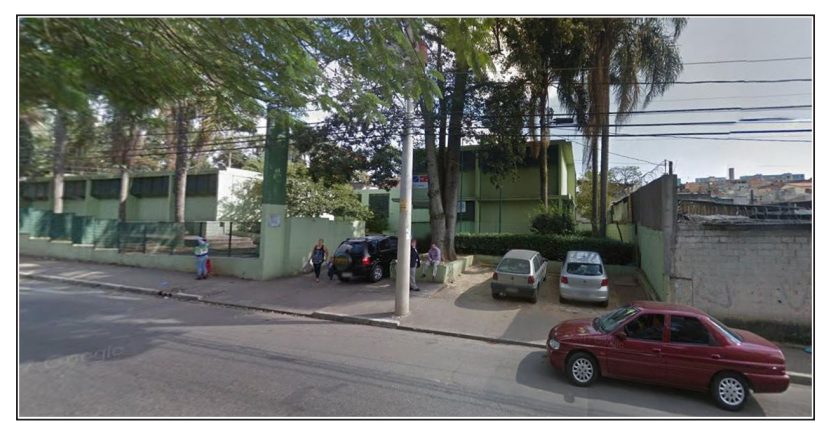

Figura 7 - UBS Dom João Nery. Estrada Dom João Nery, 3462 Fonte: Google Street View (2017).

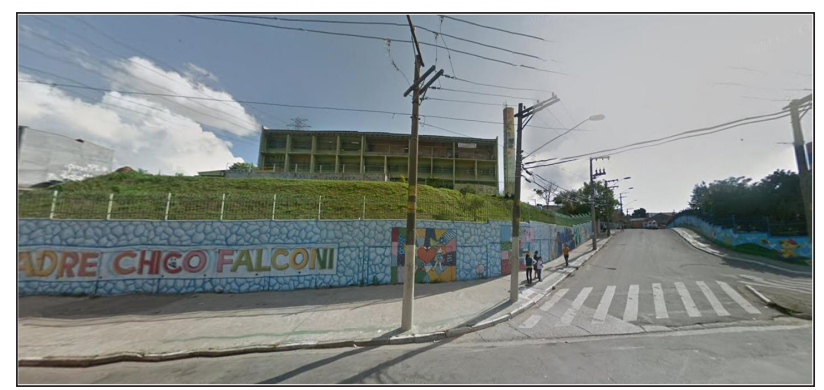

Figura 8 - EMEF Padre Chico Falconi. Rua Brilho do Sol, 96 esquina com Estrada Dom João Nery Fonte: Google Street View (2017). em várias regiões da cidade. A Lei prevê uma faixa de desapropriação de cerca de quarenta metros, como consta nas plantas n.. $26.964 / 1$ a 5, Classificação D-307, anexa à Lei. A faixa de desapropriação máxima chega a 48 metros, correspondendo a 58 lotes entre desapropriações parciais e totais, como podemos observar nas Figuras 9 e 10.

Em novembro de 2014, foram realizadas as audiências públicas para discussão do corredor. A Central Leste de Notícias, através de matéria assinada por Vander Ramos, em 19/11, relata o evento (Ramos, 2014). A matéria foi publicada ao final da audiência pública realizada pela SPTrans (São Paulo Transportes S/A), para receber contribuições para o edital de construção do Terminal de Ônibus Itaim Paulista e do Corredor Perimetral Itaim Paulista/São Mateus, pela Estrada Dom João Nery. Segundo a matéria, na desapropriação da área necessária para a implantação do Plano de Mobilidade Urbana da Prefeitura, a área foi dividida em dez lotes; contudo, no início, a proposta foi barrada pelo Tribunal de Contas do Município, que questionou a origem dos recursos para a implementação do sistema. $\mathrm{Na}$ época da matéria, o autor parecia convencido de que o corredor seria implantado e relata "a manobra da prefeitura" para conseguir viabilizar o projeto. As desapropriações incluiriam as escolas e os postos de saúde citados na resolução da aprovação do Corredor, e também afetariam as residências e o comércio local consolidados ao longo da Estrada Dom João Nery.

A matéria apresenta o depoimento de um morador e de um representante local, Edson Coqueiro, ambos contrários ao projeto. Coqueiro, à época, era presidente da Associação dos Empresários do Itaim Paulista e Conselheiro Participativo Municipal, depois candidantandose a vereador pelo PRB, nas eleições de 2016.

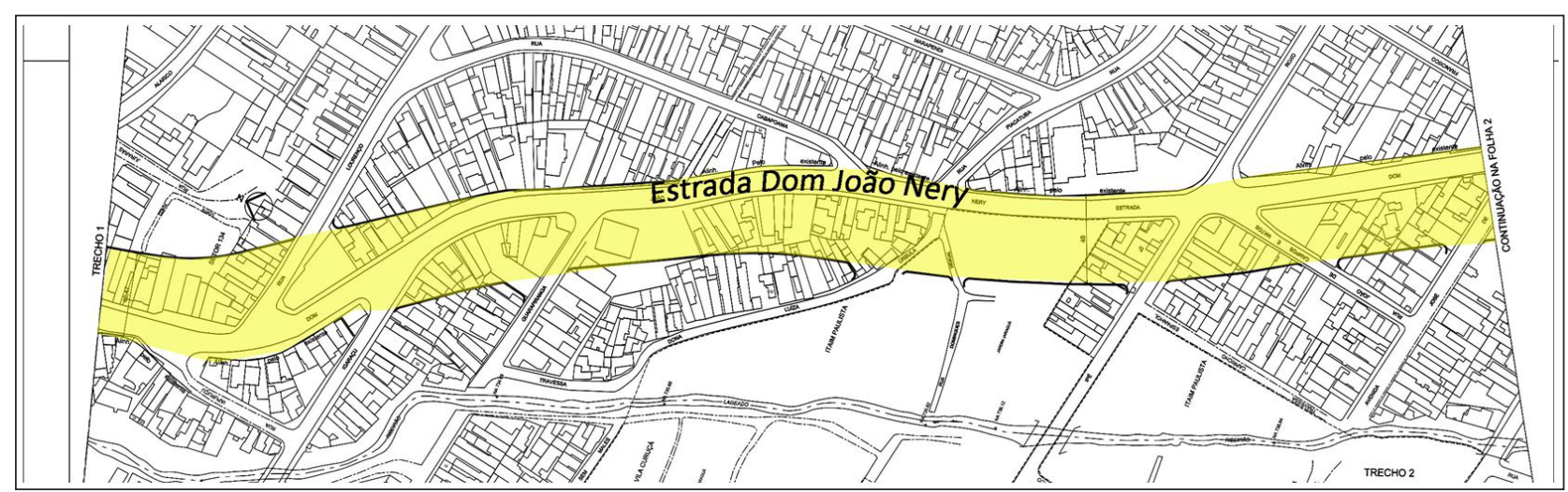

Figura 9 - Planta n. ${ }^{0}$ 26.964, em destaque a faixa de desapropriação prevista Fonte: São Paulo (2014a). 


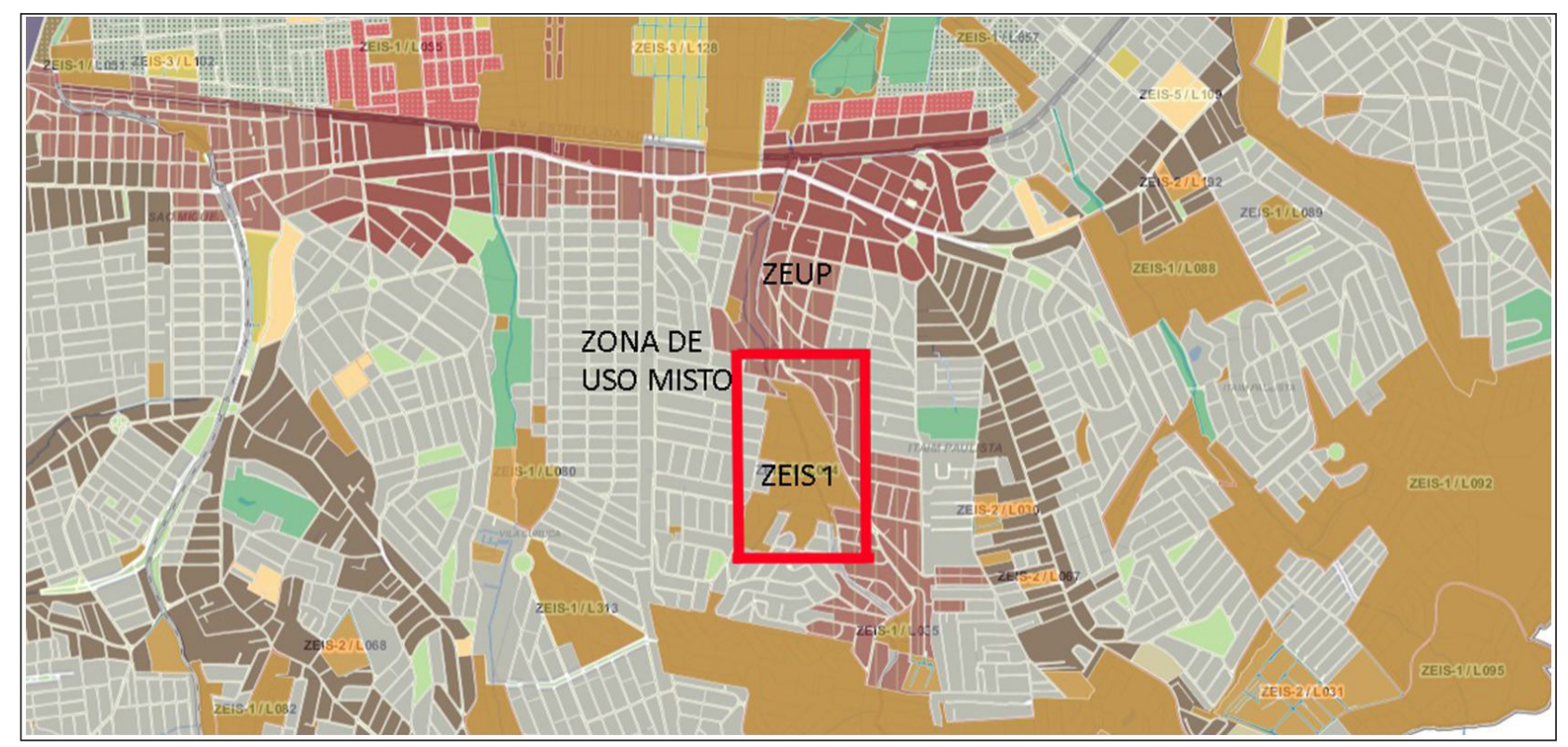

Figura 10 - Mapa de Zoneamento Lei n. ${ }^{0}$ 16.402/2016. Detalhe do mesmo trecho da Estrada Dom Joc̃o Nery mostrando a desapropriação sobre a área ZEIS 1 Fonte: Mapa das Zeis Lei n. ${ }^{1}$ 16.402/2016 (São Paulo, 2018) com intervençōes das autoras.

Setores ligados ao comércio local não estavam seguros dos benefícios do empreendimento de transformação urbana, embora todos estivessem de acordo sobre a necessidade da ligação proposta. Estimativas trazidas pelos protestantes apontavam que o corredor proposto eliminaria cerca de 10 mil empregos entre as desapropriações da área da Av. Marechal Tito, na qual seria construído o novo terminal, e da Estrada Dom João Nery, para a ampliação do viário. Os protestos realizados na Câmara Municipal de São Paulo buscaram alterar a localização do corredor de ônibus, deslocando seu trajeto da Estrada Dom João Nery para as margens do córrego do Lajeado (PL 17/2014). Foram quatro meses de reuniões comunitárias e protestos na Câmara Municipal de São Paulo, para então ser aprovado um texto substitutivo, com a alteração da localização do corredor, mas condicionando-a à análise de viabilidade prévia. As margens do Lajeado que aparecem na Figura $11-$ como as dos demais córregos das periferias urbanas - estão ocupadas por "aglomerados subnormais", isto é, um conjunto de habitações precárias em áreas de risco. As famílias seriam removidas, de qualquer modo, pela Prefeitura e algumas destas, inclusive, já haviam recebido indenizações para deixar o local.

As desapropriações necessárias para a implementação do corredor da Estrada Dom João Nery iriam incidir em zonas com ocupação já consolidada por residencias,

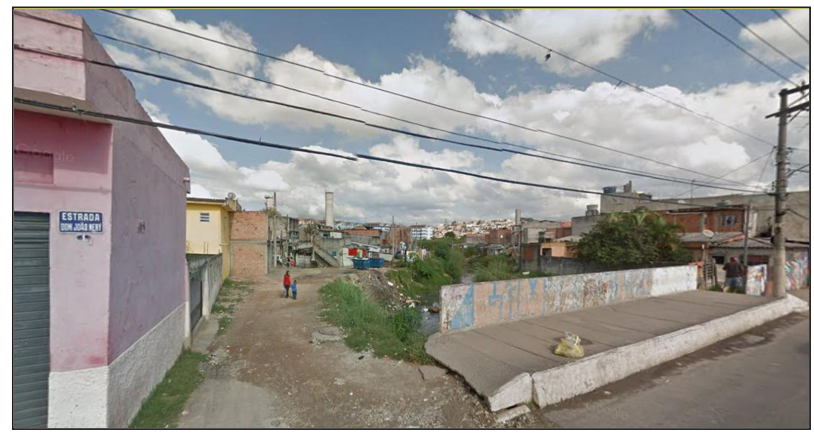

Figura 11 - Marginal do Córrego do Lajeado no cruzamento com a Estrada Dom Joc̃o Nery. Observa-se o desmoronamento da margem Fonte: Google Street View (2017).

comércio e serviços. A previsão inicial do Relatório de Impacto Ambiental da SPTrans (São Paulo, 2013b) foi de que 241 domicílios afetados seriam transferidos para a Estrada do Iguatemi e para a região sul da estrada Dom João Nery, onde, atualmente, há predominância de população de baixa renda. Por meio da pressão dos setores locais que se sentiram ameaçados pelas obras de desenvolvimento urbano, condenou-se a iniciativa; note-se que, no atual quadro de crise do país, não parece haver qualquer novo interesse para realizar a ligação prevista no Sistema Leste 2 .

A consolidação das periferias urbanas, atualmente servidas por comércio local, serviços e equipamentos, se fez de forma lenta e árdua, com o empenho da 
sociedade civil na reivindicação das ações do Estado e mesmo através do esforço próprio e da autoajuda, inclusive para as obras de urbanização, algumas das quais realizadas por sistema de mutirões. Centralidades importantes para o bairro, ao longo de vias como a Estrada Dom João Nery, podem de fato ser ameaçadas com propostas de desenvolvimento urbano, que certamente funcionariam como atrativo de capitais e empregos em áreas centrais. Por outro lado, a não implementação do sistema Leste 2 reforça a segregação espacial tão característica das relações entre centro e periferia, na cidade de São Paulo.

Martins (2006, p. 285-288), em seu estudo sobre as interações entre a região metropolitana de São Paulo e o sistema social, identifica a presença do "protagonismo do Estado" no "modelo hegemônico da realidade urbana". O autor acrescenta que o "direito à cidade" e a "cidade mercado", "embora ocupem posições antagônicas no campo" da disputa política, possivelmente funcionem "em solidariedade orgânica”, quando transpostos à espacialização da sociedade de classes. Neste sentido, as áreas de difícil renovação urbana, devida à pouca atratividade aos capitais imobiliários, seriam, por este motivo, menos atrativas para os mecanismos de renovação urbana que geralmente impulsionam a ação do Estado nas obras viárias, aumentando as relações de mobilidade entre os indivíduos e a cidade.

\section{O desenho do conflito}

É inegável que o conjunto de obras previstas, composto por um terminal e um corredor de ônibus ligando a atual estação da CPTM - que hoje é a principal conexão do bairro com o centro da cidade - com o terminal de São Mateus, localizado mais ao sul, completaria uma importante rede de integração intermodal da região leste com o centro da cidade. A integração mais eficiente do Itaim Paulista ao sistema geral de mobilidade da cidade de São Paulo dinamizaria a economia local em uma perspectiva de longo e médio prazo.

Para a implantação do corredor, como previsto inicialmente, na Estrada Dom João Nery, seria necessária uma grande área de desapropriação, e a possibilidade de elavação do Coeficiente de Aproveitamento, conforme Figura 10 da Lei de Zoneamento, se mostra essencial para que a população desapropriada seja reassentada no local. $\mathrm{O}$ uso misto proposto e o aumento das áreas residencias e de habitação de interesse social, próximas ao corredor, também, em tese, trariam uma reconfiguração urbana importante para o local, se associados a um projeto de desenvolvimento local integrado a um plano de microeconomia comunitária. Entretanto, a ausência de estratégias específicas para o desenvolvimento imobiliário em áreas periféricas tem significado um gargalo para a realização da democracia urbana.

A forma participativa de revisão do Plano Diretor e da Lei de Zoneamento foi um diferencial no processo de elaboração e aprovação dessas duas importantíssimas leis para o desenvolvimento urbano do município de São Paulo. A revisão do PDE (São Paulo, 2014b) procurou corrigir as distorções do processo participativo, que foram apontadas durante a elaboração do PDE (São Paulo, 2002). Villaça (2005, p. 85) ressalta que, para a elaboração do PDE (São Paulo, 2002), houve apenas uma reunião para toda a zona leste, isto é, 11 subprefeituras e cerca de 3,7 milhões de pessoas, que na época correspondiam a 35,4\% da população municipal. A revisão do PDE (2014) procurou corrigir essa distorção e, em 20 de julho de 2013, a audiência pública no Itaim Paulista contou com 207 pessoas e recolheu 49 contribuições (Fernandes, 2017, p. 28).

Entretanto, os protestos registrados pela imprensa local em relação à implantação do corredor de ônibus na Estrada Dom João Nery demonstram que os processos participativos e a preocupação com o desenvolvimento local presentes nas diretrizes de elaboração da revisão do PDE não foram suficientes para evitar os conflitos entre as diretrizes gerais de desenvolvimento da cidade e os setores sociais urbanos representativos no Itaim Paulista.

Por outro lado, a solução do conflito entre o plano de mobilidade e estes setores no Itaim Paulista foi o deslocamento do corredor da Estrada Dom João Nery para a via marginal ao Córrego do Lajeado. A alteração ocorre na contramão das políticas ambientais, as quais pretendem mitigar os graves problemas de abastecimento de água que a cidade de São Paulo enfrentará no futuro. Mas, tampouco, a agenda ambiental havia sido incorporada no Projeto de mobilidade realizado pela EMTU-SP Trans. As estratégias do zoneamento e da política urbana ainda estão longe de serem eficientes para enfrentar a pressão demográfica e a ocupação das áreas de risco, ao longo dos córregos urbanos e das áreas de proteção ambiental. 
Os prejuízos ambientais decorrentes do deslocamento do corredor da Av. Dom João Nery para o Córrego do Lajeado não foram reclamados por nenhum dos lados do conflito urbano que desenha a cidade e ainda estão longe de ter um lugar de destaque na democracia urbana brasileira.

\section{Referências}

Abramo, P. (Ed.) (2003). A cidade da informalidade. $O$ desafio das cidades latino-americanas. Rio de Janeiro: Livraria Sette Letras/FAPERJ.

Anelli, R., \& Leitão, A. (2014). Corredores Ambientais Urbanos: desafios para o desenvolvimento do Plano Diretor Estratégico de São Paulo, articulando as escalas metropolitana, regional e local. Anais do III Enanparq (pp. 1-16). São Paulo: ANPARQ.

Brasil. (2001, 11 de julho). Lei $n^{\circ}$ 10.257, de 10 de julho de 2001. Regulamenta os arts. 182 e 183 da Constituição Federal, estabelece diretrizes gerais da política urbana e dá outras providências. Brasília: Diário Oficial da União, seção 1.

Brasil. (2012, 4 de janeiro). Lei ${ }^{\circ} 12.587$ de 3 de janeiro de 2012. Institui as diretrizes da Política Nacional de Mobilidade Urbana. Brasília: Diário Oficial da União, seção 1, p. 1.

Bueno, L. M. M., \& Cymbalista, R. (2007). Planos Diretores: novos conceitos de planejamento territorial. São Paulo: Annablume.

Caldeira, T. P. R. (1984). A política dos outros: o cotidiano dos moradores da periferia e o que pensam do poder e dos poderosos. São Paulo: Brasiliense.

Caldeira, T. P. R. (2005). Cidade de Muros: crime, segregação e cidadania em São Paulo. São Paulo: Editora 34/Edusp.

Denaldi, R. (2009). Estratégias de enfrentamento do problema: favela. In Brasil. Ministério das Cidades. Política habitacional e a integração urbana de assentamentos precários: parâmetros conceituais, técnicos e metodológicos. Brasília: Ministério das Cidades.

Fernandes, E. (2003). Perspectivas para a renovação das políticas de legalização de favelas no Brasil. In P. Abramo (Ed.), A cidade da informalidade. $O$ desafio das cidades latinoamericanas. Rio de Janeiro: Livraria Sette Letras/FAPERJ.

Fernandes, J. S. (2017). Participação Popular na Revisão do Marco Regulatório Urbanístico. Estudo de caso: Itaim
Paulista (Relatório de Iniciação Científica). São Paulo: Universidade São Judas Tadeu.

Fundação Perseu Abramo. (2017). Percepções e valores políticos nas periferias de São Paulo. São Paulo.

Google Street View. (2017). Acesso em 26 de agosto de 2017, de https://www.google.com.br/intl/pt/streetview/

Kowarick, L., \& Caldeira Brant, V. (Ed.) (1976). São Paulo 1975 crescimento e pobreza. São Paulo: Edições Loyola.

Lara, F., \& Koury, A. P. (Ed.) (2016). Planejamento versus Participação: um falso dilema. Austin- Belo Horizonte: Nhámerica Press.

Maricato, E. T. (2011). O impasse da política urbana no Brasil. Petrópolis: Vozes.

Marques, E. C., \& Bichir, R. M. (2002). Investimentos públicos, infra-estrutura urbana e produção da periferia em São Paulo. Revista Espaço e Debates, 42, 9-30.

Martins, J. D. (2006). As Regras da Metrópole: o campo urbanístico e a ordem social na Região Metropolitana de São Paulo (Tese de doutorado). Instituto de Ciências Sociais, Universidade de Brasília, Brasília.

Ramos, V. (2014). Prefeitura retoma projeto do corredor e terminal de ônibus no Itaim Paulista. São Miguel Paulista. Recuperado em 5 de setembro de 2014, de http://www.saomiguelpaulista.com.br/portal/index. php?secao $=$ news\&id_noticia $=2718 \&$ subsecao $=4$

Rolnik, R. (2013). 10 Anos do Estatuto da Cidade: das Lutas pela Reforma Urbana às Cidades da Copa do Mundo. São Paulo. Recuperado em 4 de março de 2015, de https:// raquelrolnik.files.wordpress.com/2013/07/10-anos-doestatuto-da-cidade.pdf

Santos, O. A. Jr., \& Montandon, D. T. (Ed.) (2011). Os Planos Diretores Municipais pós-estatuto da cidade: balanço crítico e perspectivas. Rio de Janeiro: Letra Capital; Observatório das Cidades.

São Paulo (Cidade). (2002, 14 de setembro). Lei $n^{\circ}$ 13.430/2002 de 13 de setembro de 2002. Institui o Plano Diretor Estratégico e o Sistema de Planejamento e Gestão do Desenvolvimento Urbano do Município de São Paulo. São Paulo: Diário Oficial do Município de São Paulo, ano 47, n. 175.

São Paulo (Cidade). (2004, 6 de outubro). Lei $n^{\circ}$ 13.885/2004 de 25 de agosto de 2004. Estabelece normas complementares ao Plano Diretor Estratégico, institui os Planos Regionais 
Estratégicos das Subprefeituras, dispõe sobre o parcelamento, disciplina e ordena o Uso e Ocupação do Solo do Município de São Paulo. São Paulo: Diário Oficial do Município de São Paulo, ano 49, n. 189.

São Paulo (Cidade). (2010). Infocidade. População Recenseada,Taxas de Crescimento Populacional e Densidade Demográfica. Município de São Paulo, Subprefeituras e Distritos Municipais, 1980, 1991, 2000 e 2010. São Paulo: Prefeitura Municipal. Recuperado em 5 de setembro de 2017, de http://infocidade.prefeitura.sp.gov.br/htmls/7_populacao_ recenseadataxas_de_crescimento_1980_10745.html

São Paulo (Cidade). (2013a). Programa Municipal de Investimentos e Ações para Melhoria do Transporte Público. São Paulo: Secretaria Municipal de Transportes - SPTRANS.

São Paulo (Cidade). (2013b). Terminais e Sistemas Viários da Região Leste 2. Estudo de Impacto Ambiental. São Paulo: Secretaria Municipal de Transportes - SPTRANS.

São Paulo (Cidade). (2013c, 29 de novembro). Resolução $n^{\circ}$ 158/CADES/2013 de 27 de novembro de 2013. São Paulo: Diário Oficial Cidade de São Paulo, ano 58, n. 26, p. 35-38.

São Paulo (Cidade). (2014a, 8 de fevereiro). Projeto de Lei $n^{\circ}$ 01-00017/2014. Aprova melhoramentos viários necessários à implantação de corredores de ônibus e obras viárias complementares. São Paulo: Diário Oficial da Cidade de São Paulo, ano 59, n. 27.

São Paulo (Cidade). (2014b, 1 de agosto). Lei $n^{\circ}$ 16.050/2014 de 31 de julho de 2014. Aprova a Política de Desenvolvimento Urbano e o Plano Diretor Estratégico do Município de São Paulo e revoga a Lei no 13.430/2002. São Paulo: Diário Oficial Cidade de São Paulo, ano 59, n. 140 (suplemento).

São Paulo (Cidade). (2014c, 3 de julho). Lei n ${ }^{\circ}$ 16.020/2014 de 02 de julho de 2014. Aprova melhoramentos viários necessários à implantação de corredores de ônibus e obras viárias complementares; aprova e altera planos de melhoramentos e alinhamentos viários nos Distritos de Capão Redondo, Campo Limpo, Penha, Carrão, Aricanduva, São Mateus, Parque do Carmo, Cursino, Ipirange, Limão, Belenzinho, Perdizes, Santo Amaro, Sapopemba e Cangaíba, e estabelece providências correlatas bem como revoga as leis que especifica. São Paulo: Diário Oficial Cidade de São Paulo, ano 59, n. 120.

São Paulo (Cidade). (2014d). Mapa de desenvolvimento urbano (PDE/2014). São Paulo: Prefeitura Municipal. Recuperado em 27 de agosto de 2017, de http://gestaourbana.prefeitura. sp.gov.br/arquivos-pde-biblio/

São Paulo (Cidade). (2015a). Plano Diretor Estratégico do Município de São Paulo: lei municipal $n^{\circ}$ 16.050, de 31 de julho de 2014. Texto da lei ilustrado. São Paulo: Prefeitura Municipal. Recuperado em 4 de setembro de 2017, de http://gestaourbana.prefeitura.sp.gov.br/wp-content/ uploads/2015/01/Plano-Diretor-Estrat\%C3\%A9gicoLei-n\%C2\%BA-16.050-de-31-de-julho-de-2014-Textoda-lei-ilustrado.pdf

São Paulo (Cidade). (2015b). Plano de Mobilidade de São Paulo - PlanMob/2015. São Paulo: Prefeitura Municipal. Recuperado em 5 de setembro de 2017, de http://www. prefeitura.sp.gov.br/cidade/secretarias/upload/chamadas/ planmobsp_v072_1455546429.pdf

São Paulo (Cidade). (2016a, 23 de março). Lei no 16.402/2016 de 22 de março de 2016. Disciplina o parcelamento, o uso e a ocupação do solo no Município de São Paulo, de acordo com a Lei no 16.050, de 31 de julho de 2014 - Plano Diretor Estratégico (PDE). São Paulo: Diário Oficial Cidade de São Paulo, ano 61, n. 54.

São Paulo (Cidade). (2016b, 25 de fevereiro). Decreto $n^{\circ}$ $56.834 / 2016$ de 24 de fevereiro de 2016. Institui o Plano Municipal de Mobilidade Urbana de São Paulo - PlanMob/ SP 2015. São Paulo: Diário Oficial Cidade de São Paulo, ano 61 , n. 35.

São Paulo (Cidade). (2018). Mapa Digital da Cidade de São Paulo. São Paulo: Prefeitura Municipal. Recuperado em 16 de maio de 2018, de http://geosampa.prefeitura.sp.gov. br/PaginasPublicas/_SBC.aspx

São Paulo (Estado). (2013). Empresa Metropolitana de Transportes Urbanos, EMTU: Atividades. São Paulo: Governo do Estado. Recuperado em 5 de setembro de 2017, de http:// www.emtu.sp.gov.br/EMTU/pdf/ATIVIDADES-2013.pdf

Somekh, N., \& Campos Neto, C. M. (2005). Desenvolvimento local e projetos urbanos. Arquitextos, 5. Recuperado em 5 de setembro de 2017, de http://www.vitruvius.com.br/ revistas/read/arquitextos/05.059/470

Villaça, F. (2005). As ilusões do Plano Diretor São Paulo. São Paulo: Edição do autor.

Recebido: Set. 06, 2017

Aprovado: Dez. 27, 2017 